\title{
Celebrity Endorser dan Keputusan Pembelian untuk Generasi Z: Efek Mediasi Citra Merek
}

Submitted Date :

16 July 2021

Accepted Date :

11 August 2021
Stefany Jeane Tayl ${ }^{*}$ Fakultas Ekonomika dan Bisnis, UKSW, Salatiga febestefanyjeanetayl@gmail.com

Yunita Budi Rahayu Silintowe Fakultas Ekonomika dan Bisnis, UKSW, Salatiga yunita.silintowe@uksw.edu

\section{Suggested Citation:}

Aprilia, A. D., \& Hidayati, N. (2020). The Effect of Celebrity Endorsers on Purchase Decisions on the Fait Hijab Online Shop on Instagram. Advance in Economics, Business and Management Research, 115(Insyma 2020), 230234.

Abstract:

The main purpose of the study was to identify the effect of celebrity endorsers on purchasing decisions mediated by brand image variables on Pond's products. The number of samples in this study was 141 respondents who had bought Pond's products. Data collection techniques using a purposive sampling method with a questionnaire. Data were analysed with SEM AMOS 24 with the results of the study: celebrity endorser has a positive and significant effect on brand image, and brand image has a positive and significant effect on purchasing decisions, then celebrity endorser has no significant direct effect on purchasing decisions. Intervening variable testing shows that there is an indirect effect between celebrity endorsers on purchasing decisions through brand image variables.

Keywords: Brand Image; Celebrity Endorser; Purchase Decision; Z-Generation

Abstrak:

Penelitian ini dilakukan bertujuan untuk melihat pengaruh celebrity endorser terhadap keputusan pembelian yang di mediasi oleh citra merek pada produk Pond's. Jumlah sampel dalam penelitian ini adalah 141 responden yang pernah membeli produk Pond's. Teknik pengumpulan data menggunakan metode purposive sampling dengan kuesioner. Data dianalisis dengan SEM AMOS 24 dengan hasil penelitian: celebrity endorser berpengaruh positif dan signifikan terhadap citra merek, serta citra merek berpengaruh positif dan signifikan terhadap keputusan pembelian, kemudian celebrity endorser tidak berpengaruh signifikan secara langsung terhadap keputusan pembelian. Pengujian variabel intervening menunjukan bahwa terdapat pengaruh tidak langsung antara celebrity endorser terhadap keputusan pembelian melalui variabel citra merek.

Keywords: Celebrity Endorser; Citra Merek; Generasi-Z; Keputusan Pembelian

JEL Classification: M31, M37

${ }^{*}$ Corresponding Author 


\section{Latar Belakang}

Dalam bidang pemasaran, perusahaan berlomba-lomba dalam upaya menarik konsumen dengan harapan konsumen akan melakukan keputusan pembelian untuk produk yang diperdagangkan. Keputusan pembelian terjadi ketika konsumen mencari, memutuskan di antara banyak pilihan dan membeli suatu produk. Suatu merek menjadi pertimbangan bagi konsumen ketika menentukan produk yang dibeli. Jika seorang konsumen belum pernah membeli produk yang akan dibeli maka konsumen memiliki kecenderungan untuk membeli merek terkenal atau disukai.

Citra merek yang kuat mempengaruhi keputusan pembelian (Purwanto \& Suharyono, 2018). Yang dilakukan oleh perusahaan adalah membangun citra merek yang lebih unggul dari pesaing dengan berbagai cara. Salah satu cara kegiatan pemasaran dalam meningkatkan citra merek yaitu membangun persepsi konsumen melalui celebrity endorser. Perusahaan berharap, pesan akan memperoleh perhatian besar jika disampaikan oleh selebriti terkenal (Royan, 2004). Celebrity endorser juga akan meningkatkan ketertarikan seseorang terhadap merek. Jadi, celebrity endorser yaitu selebriti yang menyampaikan pesan dan dapat membuat konsumen tertarik terhadap merek. Jenis produk kosmetik sering menggunakan celebrity endorser sebagai daya tarik bagi konsumen.

Penggunaan produk kosmetik menjadi perhatian manusia sejak abad ke-19, digunakan untuk kecantikan dan kesehatan (Maknawai.net, 2018). Kosmetik banyak digunakan oleh laki-laki maupun perempuan agar terlihat tampan atau cantik dan mampu meningkatkan rasa percaya diri seseorang. Industri kosmetik di Indonesia mengalami kenaikan 20\% pada tahun 2018 dan menunjukkan empat kali lipat dari pertumbuhan ekonomi nasional 2017 (Kemenperin, 2018).

Gambar 1. Tren Penjualan Kosmetik di Indonesia

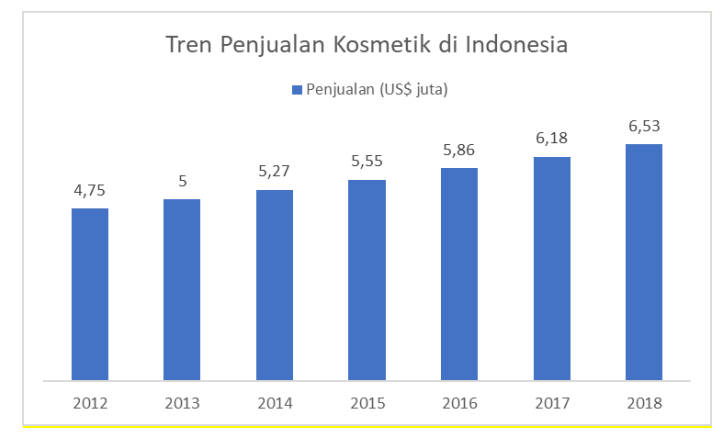

Sumber: bisnisindonesia.id (2021)

Berdasarkan Top Brand Award Fase I 2018 menunjukkan bahwa kosmetik Pond's masuk dalam peringkat pertama kategori sabun pembersih wajah, pelembab wajah, dan krim pemutih wajah (Top Brand Award, 2018).

Tabel 1. Top Brand Index Fase 12018

\begin{tabular}{llllll}
\multicolumn{2}{c}{ Sabun Pembersih Muka } & \multicolumn{2}{c}{ Pelembab Wajah } & \multicolumn{2}{c}{ Krim Pemutih Wajah } \\
\hline Brand & TBI 2018 & Brand & TBI 2018 & Brand & TBI 2018 \\
Pond's & $23.18 \%$ & Pond's & $38.82 \%$ & Pond's & $47.50 \%$ \\
Biore & $20.95 \%$ & Garnier & $17.55 \%$ & Garnier & $22.54 \%$ \\
Garnier & $17.85 \%$ & Nivea & $5.98 \%$ & Citra White & $7.92 \%$ \\
Clean \& Clear & $6.71 \%$ & Olay & $5.54 \%$ & Sariayu & $5.48 \%$ \\
Nivea & $4.63 \%$ & Wardah & $5.45 \%$ & Nivea & $3.06 \%$ \\
& & Viva & $2.94 \%$ & & \\
\hline
\end{tabular}

Sumber: Top Brand Award (2018)

Hal ini membuktikan semakin berkembang bisnis dalam bidang kosmetik, dapat dilihat dari semakin banyak produk kosmetik dengan beraneka ragam merek yang beredar, termasuk Pond's. Hadirnya produk Pond's, Unilever Indonesia berhasil menyasar konsumen remaja Indonesia dalam kategori produk perawatan wajah (Christov, 2012).

Menurut World Health Organization (WHO) dalam buku Susanto (2018), remaja adalah manusia yang berumur 10-20 tahun. Sedangkan usia remaja dianggap pantas menggunakan kosmetik yaitu 18 tahun (Permana, 2015). Usia remaja termasuk dalam generasi Z. Generasi $Z$ adalah generasi yang lahir pada tahun 1995-2012 (Stillman \& Stillman, 2018). Generasi ini dinilai lebih konsumtif atau hedonis, karena generasi ini 
dianggap sebagai generasi yang boros. Mereka mudah terpengaruh jika promosi dilakukan oleh olahragawan atau artis para remaja dan mengikuti akun media sosialnya sehingga mereka akan terpengaruh untuk membeli produk yang diendorse (Wahyuni, 2017). Menurut Prameswari (2018) generasi Z akan mempercayai merek jika memiliki dampak sosial atau positif bagi lingkungan yaitu citra dari merek itu sendiri.

Pengaruh celebrity endorser terhadap perilaku konsumen terkait erat dengan kemenarikan dan kredibilitas pada celebrity endorser yang dipersepsikan oleh konsumen (Hani et al., 2018) dan dalam penelitian tersebut menunjukkan bahwa kredibilitas merupakan faktor yang menentukan konsumen melakukan minat membeli. Dalam beberapa penelitian (Aprilia \& Hidayati, 2020; Ifeanyichukwu, 2016) menunjukkan hasil terdapat pengaruh celebrity endorser terhadap keputusan pembelian. Peran celebrity endorser dalam pengaruhnya terhadap keputusan pembelian seringkali disejajarkan dengan variabel yang lain yaitu citra merek (Bramantya \& Jatra, 2016), serta word of mouth (Shandy, 2018). Berdasarkan beberapa hasil penelitian tersebut terbukti bahwa celebrity endorser memiliki pengaruh paling tinggi terhadap keputusan pembelian (Bramantya \& Jatra, 2016; Shandy, 2018). Penelitian lain dikembangkan bahwa citra merek mampu memediasi pengaruh celebrity endorser, daya tarik iklan, dan kualitas produk terhadap keputusan pembelian (Hestyani \& Astuti, 2017), dan dalam penelitian tersebut menunjukkan bahwa celebrity endorser memiliki pengaruh paling besar.

Penelitian terdahulu yang telah dilakukan terkait celebrity endorser berfokus pada konsumen secara umum (Ifeanyichukwu, 2016; B. N. Santoso, 2018; Shandy, 2018), dan konsumen secara umum di Instagram (Aprilia \& Hidayati, 2020). Penelitian lain terkait celebrity endorser menjadikan masyarakat berusia 17 tahun ke atas (Bramantya \& Jatra, 2016; Hestyani \& Astuti, 2017; Purwanto \& Suharyono, 2018), berusia 20 sampai 44 tahun (Hani et al., 2018) dan sebagian berfokus pada mahasiswa (Anggi \& Soesanto, 2016; Tilasenda et al., 2019) sebagai responden. Dengan demikian dapat dilihat bahwa masih terdapat keterbatasan penelitian terkait celebrity endorser yang berfokus pada generasi $Z$. Hal tersebut didukung juga dengan penelitian McCormick (2016) yang mengatakan bahwa keterbatasan penelitian yang dilakukan hanya meneliti generasi millennial. Dalam penelitian McCormick (2016) menyarankan untuk meneliti pada generasi Z yang lebih peka terhadap selebriti. Dengan melihat celah dari penelitian sebelumnya, maka peneliti akan berfokus pada generasi $Z$ dalam menguji pengaruh celebrity endorser terhadap keputusan pembelian dengan citra merek sebagai variabel mediasi pada produk Pond's.

Endorse adalah promosi dengan menggunakan seseorang yang mendukung atau menyukai produk atau jasa yang ditawarkan (Kurniaini, 2017). Pengukur celebrity endorser terdiri dari empat unsur yaitu visibility, seberapa jauh popularitas selebriti; credibility, pengetahuan terhadap suatu produk yang diketahui selebriti; attraction, daya tarik selebriti; personality, seberapa besar masyarakat menyukai (nge-fans), dan kesamaan dengan target user; power, kemampuan yang dimiliki oleh selebriti untuk menarik konsumen dalam melakukan pembelian (Royan, 2004).Selebriti digunakan sebagai endorser dengan maksud agar pesan yang disampaikan oleh selebriti tersebut akan cepat dan mudah diingat oleh konsumen, sehingga konsumen kemudian akan melakukan pembelian terhadap merek tersebut (Royan, 2004). Dengan demikian dapat diartikan bahwa selebriti merupakan cerminan dari sebuah merek. Citra merek yaitu citra atas suatu merek sebagai upaya untuk menciptakan kecenderungan konsumen terhadap merek tertentu (Rahman, 2010). Hal ini berarti celebrity endorser memiliki hubungan terhadap citra merek. Pada penelitian Sujana, Giantari, \& Giantari (2017) membuktikan bahwa celebrity endorser berpengaruh signifikan terhadap citra merek. Didukung juga oleh penelitian Anggi \& Soesanto (2016) dan Putra \& Sulistyawati (2015) yang menyatakan bahwa celebrity endorser terbukti berpengaruh positif terhadap citra merek.

Citra merek yaitu citra atas suatu merek untuk menciptakan kecenderungan konsumen terhadap merek tersebut (Rahman, 2010). Menurut Suyanto (2007) asosiasi merek terdiri dari tiga yaitu atribut produk, berkaitan dengan merek atau produk seperti warna, ukuran, desain; dan yang tidak berhubungan dengan produk (harga, pemakai, citra penggunaan); manfaat produk, terdiri dari manfaat fungsional, manfaat simbolis dan manfaat berdasarkan pengalaman; sikap produk, suka atau tidak suka terhadap suatu produk. Keputusan pembelian yaitu tahap setelah niat beli dengan konsumen melakukan kegiatan pembelian yang sebenarnya (Morissan, 2010). Menurut Rahman (2010) produk merupakan sesuatu yang diproduksi oleh pabrik sedangkan merek adalah sesuatu yang dibeli oleh konsumen. Selain itu, pilihan merek terkadang didasarkan pada faktor gengsi dan emosional dalam melakukan keputusan pembelian konsumen. Dengan demikian dapat dijelaskan bahwa citra merek terdapat pengaruh terhadap keputusan pembelian. Pada penelitian Rizki \& Mudiantono (2016), 
Aprianto (2016), dan Wulandari \& Iskandar (2018) menunjukkan bahwa citra merek memiliki pengaruh signifikan terhadap keputusan pembelian. Berdasarkan temuan di atas maka diajukan hipotesis sebagai berikut:

Endorse adalah promosi dengan menggunakan orang lain yang mendukung atau menyukai produk atau jasa yang ditawarkan (Kurniaini, 2017). Keputusan pembelian yaitu tahap setelah niat beli dengan konsumen melakukan pembelian yang sebenarnya (Morissan, 2010). Menurut Royan (2004), selebriti digunakan sebagai endorser agar pesan dapat disampaikan secara cepat dan mudah diingat oleh konsumen sehingga konsumen akan membeli merek tersebut. Selebriti dapat menjadi cerminan dari sebuah merek. Dengan adanya celebrity endorser dalam sebuah produk, sangat memungkinkan untuk dapat mendorong konsumen melakukan keputusan pembelian. Hal ini didukung dari beberapa penelitian (Bramantya \& Jatra, 2016; Khan \& Lodhi, 2016; Shandy, 2018) yang menyatakan bahwa celebrity endorser terbukti berpengaruh signifikan dan positif terhadap keputusan pembelian. Berdasarkan temuan di atas maka diajukan hipotesis sebagai berikut:

Menurut Hartono (2016) celebrity endorser dapat berpengaruh terhadap citra produk karena selebriti dapat menjadi contoh masyarakat. Dengan demikian dengan adanya citra merek dapat menjadi variable yang memediasi antara celebrity endorser terhadap keputusan pembelian. Pada penelitian Hestyani \& Astuti (2017) dan Purwanto \& Suharyono, (2018) menunjukkan bahwa terdapat pengaruh signifikan dalam pengaruh citra merek sebagai variabel mediasi dalam hubungan antara celebrity endorser dan keputusan pembelian.

\section{Metode Penelitian}

Jenis penelitian yang digunakan adalah pendekatan kuantitatif, dengan tingkat kedalaman berupa analisis tataran eksplanatif. Penelitian dilakukan untuk mengetahui pengaruh celebrity endorser terhadap keputusan pembelian dengan citra merek sebagai variabel yang memediasi pada produk Pond's. Adapun populasi dalam penelitian ini adalah generasi $Z$ yang termasuk dalam kategori remaja yang melakukan kegiatan pembelian produk Pond's. Lokasi penelitian dilakukan di Kota Salatiga, Jawa Tengah. Sedangkan sampel merupakan sebagian dari suatu populasi (Suryani \& Hendryadi, 2015). Menurut Hair ukuran sampel yang sesuai untuk SEM yaitu 100-200 dengan ukuran sampel minimal berjumlah 100 (Suliyanto, 2011). Metode penentuan sampel yang digunakan adalah non-probability sampling dengan purposive sampling, dengan kriteria yaitu generasi $Z$ yang masuk kategori remaja, yang pernah melakukan pembelian produk Pond's. Dengan demikian sampel dalam penelitian ini adalah generasi $Z$ yang masuk kategori remaja yaitu 18-23 tahun di Kota Salatiga, Jawa Tengah yang pernah melakukan pembelian produk Pond's. Dalam pengambilan data primer dengan teknik survey, menggunakan instrumen berupa kuesioner. Dilakukan uji validitas dan uji reliabilitas untuk melihat kualitas instrumen yang digunakan dalam penelitian (Purwoto, 2007). Kuesioner penelitian dibagikan kepada 200 responden, namun karena terdapat data outlier maka terjadi pengurangan data menjadi 141 responden. Selanjutnya, data diolah dengan menggunakan teknik analisis structural equation modelling tidak memiliki alat uji statistik tunggal untuk mengukur atau menguji hipotesis mengenai model. Setelah dilakukan uji kesesuaian kemudian dilakukan interpretasi dari model dan melakukan modifikasi model untuk model-model yang tidak memenuhi syarat dalam uji yang dilakukan. Cut-off value untuk menilai signifikan tidaknya residual yang dihasilkan oleh model sebesar 2,58. Signifikan jika pada tingkat $5 \%$ nilai residual $\geq \pm 2,58$ (Suliyanto, 2011).

\section{Hasil}

Responden penelitian ini yaitu generasi $Z$ yang sudah pernah melakukan pembelian produk Pond's. Pengambilan data dilakukan dengan membagi kuesioner kepada responden (pelajar, mahasiswa dan pekerja). Kuesioner penelitian dibagikan kepada 200 responden, namun karena data yang digunakan tidak normal maka terjadi pengurangan outliers menjadi 141 responden yang akan dijelaskan pada hasil berikutnya. Pada uji karakteristik responden data yang digunakan yaitu 141 responden. Berdasarkan data responden diketahui jumlah responden berdasarkan usia yang paling banyak adalah 19 tahun sebanyak 34 orang (24.1\%). Hal tersebut sesuai dengan informasi yang menyatakan bahwa produk Pond's berhasil menyasar konsumen remaja Indonesia (Christov, 2012). Jika dilihat dari jenis kelamin responden didominasi perempuan (101 orang atau 71.6\%). Sesuai dengan informasi dalam Yuliastara (2018) yang menyatakan bahwa Pond's membantu masalah kulit dan memenuhi kebutuhan wanita Indonesia hal ini menunjukkan konsumen Pond's didominasi oleh wanita.

Selanjutnya pada kategori masa pemakaian produk responden paling banyak selama $<1$ tahun sebanyak 64 orang (45.4\%). Pada kategori uang saku per bulan/penghasilan responden yang menggunakan produk Pond's paling banyak memiliki uang saku per bulan/penghasilan sebesar $500.000-1.000 .000$ terdapat 44 orang $(31.2 \%)$ dan jika dilihat dari pengeluaran per hari responden terbanyak pada pengeluaran per hari sebesar < 30.000 sejumlah 66 orang $(46.8 \%)$, karena responden dalam penelitian ini sebagian besar adalah pelajar dan mahasiswa yang belum memiliki penghasilan sendiri. Produk yang dibeli responden, responden paling banyak 
membeli sabun wajah sebesar 106 orang (36.9\%). Responden lebih banyak mengetahui celebrity endorser Maudy Ayunda sebesar 73 orang (51.8\%). Berdasarkan media dalam melihat celebrity endorser, paling banyak responden melihat dari televisi sebesar 116 orang $(64,4 \%)$. Hal ini sesuai dengan informasi dari hasil monitoring iklan televisi, Pond's masuk dalam top 10 brands penayangan iklan televisi tertinggi dan berada pada urutan kedua dengan jumlah penayangan sebanyak 11.678 (Melani, 2017).

Uji validitas dan reliabilitas dilakukan dengan menggunakan SPSS 22 pada data yaitu sebanyak 200 responden. Pada penelitian utama seluruh pertanyaan dinyatakan valid berdasarkan hasil yaitu hasil lebih besar dari $r_{\text {tabel }}$ yang telah ditentukan yaitu sebesar 0,138 . Sedangkan untuk hasil uji reliabilitas menunjukkan bahwa setiap variabel dinyatakan reliable atau konsisten karena memiliki nilai Cronbach Alpha $>0,50$. Berdasarkan hasil uji kualitas instrumen menunjukkan seluruh data hasil penelitian utama dinyatakan valid dan indikator dapat mengukur pernyataan secara konsisten (Lampiran 1).

Sebelum dilakukan uji hipotesis dengan menggunakan SEM maka dilakukan uji normalitas karena ketentuan dari SEM distribusi data harus normal (Haryono, 2017). Berdasarkan hasil (Lampiran 2), menunjukkan secara univarite dengan melihat c.r. skewness dan c.r. kurtosis data tidak terdistribusi normal karena terdapat data yang berada di luar nilai kritis $(-2,58$ sampai $+2,58)$. Sedangkan secara multivariate sebaran data tidak terdistribusi normal karena memiliki angka 14,722 berada di atas batas yaitu $+2,58$. Oleh karena seluruh data dinyatakan tidak terdistribusi normal, maka dilakukan uji outliers untuk membuat data menjadi normal. Uji dilakukan dengan melakukan pengurangan responden terhadap data yang outliers. Sehingga jumlah data berkurang dari 200 responden menjadi 141 responden. Dilakukan uji normalitas kembali setelah pengurangan responden. Berdasarkan hasil (Lampiran 3), secara univariate dan multivariate menunjukkan bahwa data terdistribusi normal karena berada di antara batas $(-2,58$ sampai $+2,58)$. Data yang digunakan adalah data terhadap 141 responden setelah data dinyatakan terdistribusi normal. Berikut adalah hasil uji kesesuaian model:

Tabel 2. Hasil Pengujian Model Awal 141 Responden

\begin{tabular}{cccc}
\hline $\begin{array}{c}\text { Indeks Model Goodness } \\
\text { of Fit }\end{array}$ & Cut-off Value & Hasil Model & Evaluasi Model \\
\hline Uji Chi-square & $<159,8135$ & 360,816 & Marginal \\
RMSEA & $0,05-0,08$ & 0,111 & Buruk \\
GFI & $\geq 0,90$ & 0,764 & Buruk \\
AGFI & $\geq 0,90$ & 0,695 & Buruk \\
TLI & $\geq 0,90$ & 0,783 & Buruk \\
CFI & $\geq 0,90$ & 0,813 & Marginal \\
NFI & $\geq 0,90$ & 0,738 & Buruk \\
RFI & $\geq 0,90$ & 0,696 & Buruk \\
IFI & $\geq 0,90$ & 0,816 & Marginal \\
\hline
\end{tabular}

Sumber: Data Diolah (2020)

Berdasarkan Tabel 2 masih banyak nilai yang buruk dan sedikit nilai yang baik. Oleh karena itu dilakukan modifikasi dengan membuang beberapa item dalam setiap variabel.

Tabel 3. Hasil Modifikasi Model Akhir 141 Responden

\begin{tabular}{cccc}
\hline $\begin{array}{c}\text { Indeks Model Goodness } \\
\text { of Fit }\end{array}$ & Cut-off Value & Hasil Model & Evaluasi Model \\
\hline Uji Chi-square & $<81,38102$ & 105,695 & Marginal \\
RMSEA & $0,05-0,08$ & 0,071 & Baik \\
GFI & $\geq 0,90$ & 0,900 & Baik \\
AGFI & $\geq 0,90$ & 0,853 & Marginal \\
TLI & $\geq 0,90$ & 0,929 & Baik \\
CFI & $\geq 0,90$ & 0,944 & Baik \\
NFI & $\geq 0,90$ & 0,876 & Marginal \\
RFI & $\geq 0,90$ & 0,845 & Marginal \\
IFI & $\geq 0,90$ & 0,945 & Baik \\
\hline
\end{tabular}

Sumber: Data Diolah (2020) 
Berdasarkan Tabel 3 dapat disimpulkan secara keseluruhan merupakan Fit Model yang dapat diterima. Menurut Haryono (2017) penilaian goodness of fit minimal berdasarkan 5 (lima) kriteria. Selain itu, peneliti tidak dituntut memenuhi seluruh kriteria goodness of fit dalam penelitian empiris.

Selanjutnya dilakukan pengujian terhadap 4 hipotesis menggunakan nilai t-Value dengan tingkat signifikansi 0,05. Jika Critical Ratio (C.R.) $\geq 1,967$ atau nilai probabilitas $(P) \leq 0,05$ maka $\mathrm{H}_{0}$ ditolak (hipotesis diterima). Berikut hasil pada pengolahan AMOS 24.00:

Tabel 4. Uji Hipotesis

\begin{tabular}{lllll}
\hline & & & C.R. & P \\
Citra Merek & $\leftarrow$ & Celebrity Endorser & 3,507 & ${ }^{* * *}$ \\
Keputusan Pembelian & $\leftarrow$ & Citra Merek & 3,803 & ${ }^{* * *}$ \\
Keputusan Pembelian & $\leftarrow$ & Celebrity Endorser & $-1,671$ & 0,095 \\
\hline
\end{tabular}

Sumber: Data Diolah (2020)

Adapun hasil pengujian seluruh hipotesis:

a. $\mathrm{H}_{1}$ : Celebrity endorser berpengaruh positif dan signifikan terhadap citra merek pada produk Pond's.

Berdasarkan hasil diperoleh nilai C.R. sebesar $3,507 \geq 1,967$ dan nilai probabilitas ${ }^{* \star *} \leq 0,05$. Sehingga $H_{1}$ diterima, hal tersebut menunjukkan bahwa celebrity endorser yang digunakan dapat mempengaruhi citra merek produk Pond's.

b. $\mathrm{H}_{2}$ : Citra merek berpengaruh positif dan signifikan terhadap keputusan pembelian pada produk Pond's.

Nilai C.R. $3,803 \geq 1,967$ dan nilai probabilitas ${ }^{* *} \leq 0,05$. Sehingga $\mathrm{H}_{2}$ diterima, hal tersebut menunjukkan bahwa citra merek yang dimiliki dapat mempengaruhi keputusan pembelian produk Pond's.

c. $\mathrm{H}_{3}$ : Celebrity endorser tidak signifikan pengaruhnya terhadap keputusan pembelian pada produk Pond's.

Berdasarkan hasil didapat nilai C.R. $-1,671 \leq 1,967$ dan nilai probabilitas $0,095 \geq 0,05$. Sehingga $\mathrm{H}_{3}$ ditolak, karena hal tersebut tidak menunjukkan bahwa celebrity endorser yang digunakan dapat mempengaruhi keputusan pembelian produk Pond's secara langsung.

Untuk hasil pengaruh langsung dan pengaruh tidak langsung adalah sebagai berikut:

Tabel 5. Pengaruh Langsung

\begin{tabular}{lccc} 
& Celebrity Endorser & Citra Merek & Keputusan Pembelian \\
Citra Merek & 0,784 & 0,000 & 0,000 \\
Keputusan Pembelian & $-0,305$ & 1,055 & 0,000 \\
\hline
\end{tabular}

Sumber: Data Diolah (2020)

Tabel 6. Pengaruh Tidak Langsung

\begin{tabular}{lccc}
\hline & Celebrity Endorser & Citra Merek & Keputusan Pembelian \\
\hline Citra Merek & 0,000 & 0,000 & 0,000 \\
Keputusan Pembelian & 0,827 & 0,000 & 0,000 \\
\hline
\end{tabular}

Sumber: Data Diolah (2020)

Berdasarkan gambar 2 pengaruh langsung celebrity endorser terhadap keputusan pembelian memiliki pengaruh sebesar -0.305 . Sedangkan pengaruh tidak langsung celebrity endorser terhadap keputusan pembelian sebesar 0,827 . Karena pengaruh langsung lebih kecil dari pengaruh tidak langsung, maka dapat disimpulkan bahwa citra merek merupakan variabel intervening.

d. $\mathrm{H}_{4}$ : Terdapat pengaruh tidak langsung antara celebrity endorser dan keputusan pembelian dengan variabel citra merek sebagai variabel yang memediasi.

Berdasarkan hasil didapat nilai pengaruh langsung lebih kecil dari pada pengaruh tidak langsung yaitu $0,305<0,827$. Sehingga $\mathrm{H}_{4}$ diterima, hal tersebut menunjukkan bahwa citra merek sebagai variabel mediasi dapat mempengaruhi keputusan pembelian produk Pond's. 
Gambar 2. Pengaruh Langsung, Pengaruh Tidak Langsung

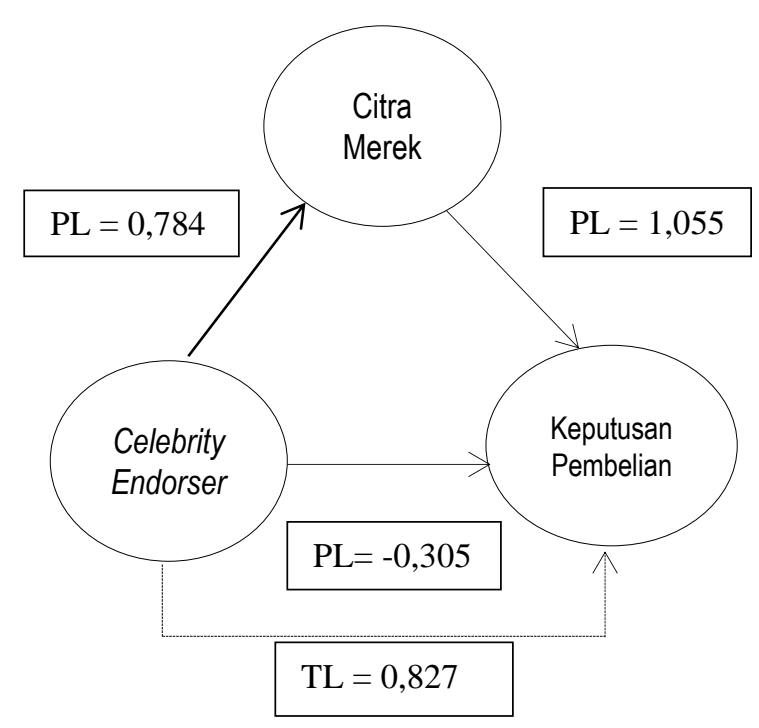

Sumber : Data Diolah (2020)

Keterangan: $\mathrm{PL}$ = pengaruh tidak langsung, dengan garis penuh (full line)

$\mathrm{TL}=$ pengaruh tidak langsung, dengan garis putus (dot line)

\section{Pembahasan}

\section{Celebrity Endorser terhadap Citra Merek}

Penelitian ini berhasil membuktikan terdapat pengaruh antara variabel celebrity endorser terhadap citra merek dengan nilai signifikansi sebesar nilai C.R. $3,507 \geq 1,967$ dan nilai probabilitas ${ }^{* * *} \leq 0,05$. Penelitian ini mendukung penelitian yang dilakukan (Sabdillah et al., 2017); Sujana et al. (2017); Anggi \& Soesanto (2016); Putra \& Sulistyawati (2015); Amalia et al. (2019); dan Anggraeni \& Kurniawati (2020) yang menunjukkan bahwa celebrity endorser memiliki pengaruh positif signifikan terhadap citra merek. Dengan demikian semakin baik celebrity endorser yang terdapat pada produk Pond's, akan meningkatkan citra merek dari produk Pond's bagi kalangan generasi Z. Hal-hal yang perlu mendapat perhatian bagi pihak Pond's terkait celebrity endorser yang perlu dimiliki supaya dapat menarik keputusan pembelian bagi generasi $Z$ adalah pilihlah selebriti yang sudah terkenal, selebriti yang disukai masyarakat, selebriti yang memiliki pengetahuan terkait produk yang di endorse, dan selebriti mampu menampilkan gaya bicara yang dapat meyakinkan konsumen. Penelitian ini bertolak belakang dengan hasil penelitian Nur \& Rahmidani (2020) yang menyatakan bahwa celebrity endorser tidak mempengaruhi citra merek produk pembersih wajah merek Garnier.

\section{Citra Merek terhadap Keputusan Pembelian}

Hasil penelitian ini menunjukkan pengaruh antara citra merek dan keputusan pembelian dengan nilai signifikansi sebesar nilai C.R. $3,803 \geq 1,967$ dan nilai probabilitas ${ }^{* * *} \leq 0,05$. Hasil penelitian ini mendukung penelitian Rizki \& Mudiantono (2016); Aprianto (2016); Priskila et al. (2016); Wulandari \& Iskandar (2018); Andrianto et al. (2016); Suyandi \& Yuliati (2020); dan Sari \& Manurung (2020) yang menyatakan bahwa citra merek berpengaruh signifikan terhadap keputusan pembelian. Hal ini berarti semakin baik citra merek yang dimiliki produk Pond's, maka akan meningkatkan dampak positif yaitu konsumen generasi $Z$ akan tertarik untuk melakukan pembelian. Pihak penjual perlu memperhatikan upaya dalam meningkatkan citra merek konsumen dengan cara menggunakan merek yang mudah diingat oleh konsumen, merek produk memberikan harga yang relatif terjangkau, kemasan produk praktis digunakan, mencerminkan generasi muda, membuat tampil percaya diri, dan konsumen menyukai produk yang diberikan oleh merek Pond's. Namun penelitian ini bertolak belakang dengan penelitia Febriyanti \& Anik (2016); Astuti \& Iriani (2019) dan Septiyani et al. (2019) yang menyatakan bahwa citra merek tidak mempengaruhi keputusan pembelian. 


\section{Celebrity Endorser terhadap Keputusan Pembelian}

Penelitian ini tidak berhasil membuktikan bahwa terdapat pengaruh antara variabel celebrity endorser terhadap variabel keputusan pembelian, karena memiliki nilai sebesar C.R. $-1,671 \geq 1,967$ dan nilai probabilitas $0,095 \leq$ 0,05 . Hasil dalam penelitian ini tidak sesuai dengan penelitian yang dilakukan oleh Shandy (2018); Roshan \& Sudiksa (2019); Andrianto et al. (2016); Astuti \& Iriani (2019); Septiyani et al., (2019); dan Sari \& Manurung (2020) bahwa celebrity endorser berpengaruh terhadap keputusan pembelian. Hasil penelitian ini sejalan dengan penelitian Handayani (2017); Suyandi \& Yuliati (2020); dan Priskila et al. (2016) bahwa celebrity endorser tidak berpengaruh signifikan terhadap keputusan pembelian, sehingga selebriti tidak mempengaruhi secara langsung dalam keputusan membeli produk. Dari hasil penelitian ini maka dapat diketahui bahwa ketika terdapat selebriti sedang memperkenalkan produk, tidak serta merta akan mempengaruhi konsumen generasi $Z$ dalam pembelian produk.

\section{Celebrity Endorser terhadap Keputusan Pembelian melalui Citra Merek}

Hasil penelitian membuktikan bahwa variabel citra merek mampu memediasi variabel celebrity endorser dan keputusan pembelian. Pengaruh langsung antara celebrity endorser dan keputusan pembelian sebesar -0.305 . Sedangkan pengaruh tidak langsung antara celebrity endorser terhadap keputusan pembelian sebesar 0,827. Oleh karena pengaruh langsung lebih kecil dari pengaruh tidak langsung, dengan demikian citra merek merupakan variabel intervening. Berdasarkan penelitian yang dilakukan oleh Roshan \& Sudiksa (2019) dan Hestyani \& Astuti (2017) yang menyatakan bahwa terdapat pengaruh signifikan dalam pengaruh citra merek sebagai variabel mediasi dalam hubungan celebrity endorser dan keputusan pembelian. Jika hanya melihat pengaruh celebrity endorser terhadap keputusan pembelian Pond's hasilnya tidak signifikan, maka harus melalui citra merek untuk memediasi hubungan antara celebrity endorser dan keputusan pembelian pada produk Pond's. Dengan demikian dapat dilihat bahwa terjadi full mediation citra merek dalam pengaruh celebrity endorser terhadap keputusan pembelian konsumen generasi $Z$.

\section{Kesimpulan}

Hasil penelitian menunjukkan bahwa celebrity endorser berpengaruh positif dan signifikan terhadap citra merek, dan citra merek memiliki pengaruh positif dan signifikan terhadap keputusan pembelian. Temuan lain menunjukkan bahwa variabel celebrity endorser tidak berpengaruh secara langsung terhadap variabel keputusan pembelian, namun terdapat pengaruh tidak langsung antara variabel celebrity endorser terhadap keputusan pembelian dengan citra merek sebagai variabel yang memediasi. Sehingga dapat disimpulkan bahwa citra merek sangat penting ketika perusahaan menggunakan celebrity endorser dalam memperkenalkan produknya khususnya bagi generasi $Z$, sehingga perlu diyakinkan bahwa dengan celebrity endorser yang digunakan harus mampu meningkatkan citra merek dari produk yang di endorse untuk menciptakan keputusan pembelian konsumen. Celebrity endorser dalam penelitian ini masih meneliti seluruh celebrity endorser yang masih digunakan Pond's, tidak difokuskan pada satu selebriti dengan kata lain penilaian celebrity endorser ditujukan untuk beberapa selebriti dalam penelitian ini. Penelitian selanjutnya dapat menggunakan variabel celebrity endorser difokuskan pada satu selebriti agar penilaian hasil penelitian juga terfokus pada satu selebriti.

\section{Daftar Pustaka}

Almana, L. O., Sudarmanto, \& Wekke, I. S. (2018). Tata Kelola Perguruan Tinggi Berbasis Akreditasi - La Ode Almana, Sudarmanto, dan Ismail Suardi Wekke - Google Books. Deepublish. https://books.google.co.id/books?id=51xHDwAAQBAJ\&printsec=frontcover\&source=gbs_ge_summary_r\&c $\mathrm{ad}=0 \# \mathrm{v}=$ onepage $\& \mathrm{q} \& \mathrm{f}=\mathrm{false}$

Amalia, N., Nuringwahyu, S., \& Krisdianto, D. (2019). Pengaruh Celebrity Endorser terhadap Brand Image pada Iklan Produk Wardah. Jiagabi, 8(2), 113-120. http://riset.unisma.ac.id/index.php/jiagabi/article/view/2124

Andrianto, N. F., Sutrasmawati, E., Manajemen, J., Ekonomi, F., Semarang, U. N., \& Artikel, I. (2016). Pengaruh Celebrity Endorser dan Brand Image pada Proses Keputusan Pembelian. Management Analysis Journal, 5(2), 104-109. https://doi.org/10.15294/maj.v5i2.8055

Anggi, V. F., \& Soesanto, H. (2016). Analis Pengaruh Daya Tarik Iklan dan Selebriti Endorser Pada Promo Ada Aqua dengan Citra Merek Sebagai Variabel Intervening (Studi Kasus pada Mahasiswa S1 di Jawa Tengah dan DIY). Diponegoro Journal Of Management, 5(3), 1-14. https://ejournal3.undip.ac.id/index.php/djom/article/viewFile/14683/14207

Anggraeni, M., \& Kurniawati, R. (2020). Pengaruh Celebrity Endorser dan Persepsi Kualitas Melalui Citra Merek 
Terhadap Loyalitas. Jurnal Kalibrasi, 17(1), 39-42. https://doi.org/10.33364/kalibrasi/v.17-1.738

Aprianto, R. (2016). Pengaruh Brand Image dan Word Of Mouth Communication terhadap Keputusan Pembelian Kompor Gas Rinnai pada Konsumen Kelurahan Cereme Taba Kota Lubuk Linggau. Jurnal IImiah Orasi Bisnis, 16(November), 72-87. http://jurnal.polsri.ac.id/index.php/admniaga/article/view/676/509

Aprilia, A. D., \& Hidayati, N. (2020). The Effect of Celebrity Endorsers on Purchase Decisions on the Fait Hijab Online Shop on Instagram. Advance in Economics, Business and Management Research, 115(Insyma 2020), 230-234. http://creativecommons.org/licenses/by-nc/4.0/

Astuti, D. T., \& Iriani, F. (2019). Apakah Celebrity Endorsement Produk Halal dan Citra Merek Berpengaruh Terhadap Keputusan Pembelian SkinCare Safi? STIE BPD Accounting Forum, 1, 537-549.

bisnisindonesia.id. (2021). Bisnis Indonesia Prospek Industri Kosmetik Kian Cantik. https://bisnisindonesia.id/article/prospek-industri-kosmetik-kian-cantik

Bramantya, Y. B., \& Jatra, M. (2016). Pengaruh Celebrity Endorser Dan Brand Image Terhadap Keputusan Pembelian Yamaha Jupiter Mx Di Kota Denpasar. E-Jurnal Manajemen Unud, 5(3), 1745-1771. https://media.neliti.com/media/publications/255237-pengaruh-celebrity-endorser-dan-brand-im6b860004.pdf

Christov. (2012). Strageti Cerdas Pond's Mendekati Konsumen. Berita-Bisnis.Com. http://www.beritabisnis.com/marketing/764--strategi-cerdas-ponds-mendekati-konsumen.html

Febriyanti, R. S., \& Anik, W. (2016). Pengaruh Celebrity Endorser Dan Brand Image Terhadap Keputusan Pembelian Melalui Minat Beli. Jurnal IImu Dan Riset Manajemen2, 5(5), 1-18.

Hani, S., Marwan, A., \& Andre, A. (2018). The Effect of Celebrity Endorsement on Consumer Behavior : Case of the Lebanese Jewelry Industry. Arab Economic and Business Journal, 13(2), 190-196. https://doi.org/10.1016/j.aebj.2018.11.002

Hartono. (2016). Pengertian dan Penggunaan Selebritis Sebagai Endorser. Gomarketingstrategic.Com. https://www.gomarketingstrategic.com/pengertian-dan-penggunaan-selebritis-sebagai-endorser/

Haryono, S. (2017). Metode SEM untuk Penelitian Manajemen dengan AMOS LISREL PLS. Luxima Metro Media.

Hestyani, A. D., \& Astuti, S. R. T. (2017). Analisis Pengaruh Celebrity Endorser, Daya Tarik Iklan, Kualitas Produk terhadap Keputusan Pembelian dengan Brand Image sebagai Variabel Intervening (Studi pada Konsumen yang Menggunakan Masker Wajah Mustika Ratu di Kota Semarang). Diponegoro Journal Of Management, 6(2), 1-11. https://ejournal3.undip.ac.id/index.php/djom/article/viewFile/17475/16728

Ifeanyichukwu, C. D. (2016). Effect of Celebrity Endorsements on Consumers Purchase Decision in Nigeria. International Research Journal of Management, IT \& Social Sciences, 3(9), 120-128. https://sloap.org/journals/index.php/irimis/article/view/420

Kemenperin. (2018). Industri Kosmetik Nasional Tumbuh 20\%. Kemenperin. http://www.kemenperin.go.id/artikel/18957/Industri-Kosmetik-Nasional-Tumbuh-20

Khan, A., \& Lodhi, S. (2016). Influence of Celebrity Endorsement on Consumer Purchase Decision: A Case of Karachi. Imperial Journal of Interdisciplinary Research, 2(1), 102-111. https://doi.org/10.1186/1687-18472012-104

Kurniaini, L. (2017). 50 Ide Bisnis Bermodal 5 Jutaan. Stiletto Book.

Maknawai.net. (2018). Pengertian Kosmetik, Sejarah dan Penggolongannya - maknawi.net. Maknawi.Net. https://maknawi.net/pengertian-kosmetik-sejarah-dan-penggolongannya/

McCormick, K. (2016). Celebrity endorsements: Influence of a product-endorser match on Millennials attitudes and purchase intentions. Journal of Retailing and Consumer Services, 32, 39-45. https://doi.org/10.1016/J.JRETCONSER.2016.05.012

Melani, A. (2017). Intip 4 Industri Penguasa Iklan Televisi. Www.Liputan6.Com. https://www.liputan6.com/bisnis/read/2928444/intip-4-industri-penguasa-iklan-televisi

Morissan. (2010). Periklanan: Komunikasi Pemasaran Terpadu. Prenadamedia Group.

Nur, K., \& Rahmidani, R. (2020). Pengaruh Celebrity Endorser dan Iklan Vidio terhadap Brand Image Produk Pembersih Wajah Garnier pada Mahasiswi Universitas Negeri Padang. Jurnal Ecogen, 3(2), 319. https://doi.org/10.24036/jmpe.v3i2.8958

Permana, R. W. (2015). Ini Usia yang Tepat untuk Gadis Mulai Memakai Make Up. Merdeka.Com. 
https://www.merdeka.com/gaya/ini-usia-yang-tepat-untuk-gadis-mulai-memakai-make-up.html

Prameswari, G. D. (2018). Karakter Gen Z untuk Strategi Pemasaran. Dailysocial.Id. https://dailysocial.id/post/karakter-gen-z-untuk-strategi-pemasaran

Priskila, E. K., Sembiring, C. F., \& Mangani, K. S. (2016). Analisis Keputusan Pembelian Di Tokopedia Yang Dipengaruhi Celebrity Endorser, Brand Image, Kelompok Referensi Dan Usia. Fundamental Management Journal, $9220(1), 1$.

Purwanto, U. Y., \& Suharyono, S. (2018). Pengaruh Celebrity Endorser terhadap Citra Merek dan Dampaknya pada Keputusan Pembelian (Survei kepada Konsumen Malang Strudel di Outlet Singosari, Kab. Malang). Jurnal Administrasi Bisnis, 56(1), 1-5. https://doi.org/10.1073/pnas.0500613102

Purwoto, A. (2007). Panduan Laboratorium Statistik Inferensial. Grasindo.

Putra, I. K. T. D., \& Sulistyawati, E. (2015). Peran Brand Image dalam Memediasi Pengaruh Celebrity Endorser terhadap Niat Beli. E-Jurnal Manajemen Unud, 4(6), 1722-1734. https://media.neliti.com/media/publications/255133-peran-brand-image-dalam-memediasi-pengarc7a9ad57.pdf

Rahman, A. (2010). Strategi Dahsyat Marketing Mix for Small Business: Cara Jitu Merontokkan Pesaing. TransMedia Pustaka.

Rizki, S. P., \& Mudiantono. (2016). Analisis Pengaruh Brand Ambassador, Kualitas Produk dan Harga Terhadap Brand Image serta Dampaknya Terhadap Keputusan Pembelian. Diponegoro Journal of Management, 5(2), 1-12. https://ejournal3.undip.ac.id/index.php/djom/article/view/13854/13404

Roshan, P. A. A., \& Sudiksa, I. B. (2019). Peran Brand Image Memediasi Pengaruh Celebrity Endorser Terhadap Purchase Intention. E-Jurnal Manajemen Universitas Udayana, 8(8), 5164. https://doi.org/10.24843/ejmunud.2019.v08.i08.p17

Royan, F. M. (2004). Marketing Celebrities: Selebriti dalam Iklan dan Strategi Selebriti Memasarkan Diri Sendiri. PT Elex Media Komputindo.

Sabdillah, R., Hidayat, R., \& Lubis, D. S. W. (2017). Influence of Celebrity Endorser Raisa Andriana in Advertisement on Magnum Ice Cream Brand Image on the Transmart Costumers. Journal Online Jaringan Pengajian Seni Bina, 10(1), 112-115. https://doi.org/10.31227/osf.io/q4z2d

Santoso, B. N. (2018). The Influence of Celebrity Endorsement in Social Media on Purchase Decision Through Perceived Value and Customer Attitude as Intervening Variabel in Souvenir Product in Surabaya. Petra Business \& Management Review, 4(2), 134-147.

Santoso, S. (2018). Konsep Dasar dan Aplikasi SEM dengan AMOS 24. PT Elex Media Komputindo.

Sari, I. N., \& Manurung, H. P. (2020). Pengaruh Celebrity Endorser, Brand Image, Dan Brand Trust Terhadap Keputusan Pembelian Produk Handphone Samsung Di Kabupaten Asahan (Studi Kasus Mahasiswa Fakultas Ekonomi Universitas Asahan). Jurnal Manajemen, Ekonomi Sains, 1(2).

Septiyani, R., Rakhmawati, S., \& Budiasih. (2019). Pengaruh Citra Merek, Kualitas Produk, Persepsi Harga, Celebrity Endorser Dan Iklan Terhadap Keputusan Pembelian Kosmetik Wardah. Prosiding Seminar Nasional Indonesian R Summit, 195-209.

Shandy, B. (2018). The Effect of Celebrity Endorser and WOM on Purchase Decision of Yamaha Motor. Jurnal Digest Marketing, 3(1), 7-14. https://online-journal.unja.ac.id/index.php/digest/article/view/4395

Stillman, D., \& Stillman, J. (2018). Generasi Z: Memahami Karakter Generasi Baru yang Akan Mengubah Dunia Kerja. PT Gramedia Pustaka Utama.

Sujana, M. S. A. S., Giantari, I. G. A. K., \& Giantari, K. (2017). Peran Brand Image Memediasi Hubungan Celebrity Endorser dengan Purchase Intention. Forum Keuangan Dan Bisnis Indonesia (FKBI), 6, 313-324. http://fkbi.akuntansi.upi.edu/

Suliyanto. (2011). Ekonometrika Terapan: Teori dan Aplikasi dengan SPSS. Andi Offset.

Suryani, \& Hendryadi. (2015). Metode Riset Kuantitatif: Teori dan Aplikasi pada Penelitian Bidang Manajemen dan Ekonomi Islam. Prenadamedia Group.

Susanto, A. (2018). Bimbingan dan Konseling di Sekolah: Konsep, Teori, dan Aplikasinya. Prenadamedia Group.

Suyandi, \& Yuliati, A. L. (2020). Pengaruh Celebrity Endorser (Syahrini) Dan Brand Image Terhadap Purchase Decision Konsumen Shopee. E-Proceeding of Management, 7(2), 3658-3664.

Suyanto, M. (2007). Marketing Strategy: Top Brand Indonesia. Andi Offset.

Tilasenda, F., Budiwati, H., \& Fauziah, A. (2019). The Effect Of Celebrity Endorse and Brand Images on Purchase Decisions (Case Study On Private College Students In Oppo Handphone Buyers). Progress Conference, 2(2), 303-307. http://proceedings.stiewidyagamalumajang.ac.id/index.php/progress

Top Brand Award. (2018). Top Brand Index Beserta Kategori Lengkap | Top Brand Award. https://www.topbrand- 
award.com/top-brand index/?tbi_year=2018

Wahyuni, N. D. (2017). Generasi Z Diprediksi Jadi Generasi Konsumtif, Apa Alasannya? Www.Liputan6.Com. https://www.liputan6.com/bisnis/read/3110014/generasi-z-diprediksi-jadi-generasi-konsumtif-apa-alasannya

Wulandari, R. D., \& Iskandar, D. A. (2018). Pengaruh Citra Merek dan Kualitas Produk Terhadap Keputusan Pembelian Pada Produk Kosmetik. Jurnal Riset Manajemen Dan Bisnis (JRMB) Fakultas Ekonomi UNIAT, 3(1), 11-18. https://doi.org/10.1016/S0014-5793(99)00359-2

Yuliastara, A. (2018). Pond's Perkuat Bisnis Unilever di Pasar Kosmetik Dalam Negeri. Cnbcindonesia.Com. https://www.cnbcindonesia.com/lifestyle/20180222124313-33-5106/ponds-perkuat-bisnis-unilever-di-pasarkosmetik-dalam-negeri

Lampiran 1. Uji Validitas dan Reliabilitas

\begin{tabular}{|c|c|c|c|c|c|}
\hline No & Variabel & Indikator & Koefisien Korelasi & Koefisien Cronbach Alpha & Kesimpulan \\
\hline 1 & Celebrity Endorser & $\begin{array}{l}\text { CE } 1 \\
\text { CE } 2 \\
\text { CE } 3 \\
\text { CE } 4 \\
\text { CE } 5\end{array}$ & $\begin{array}{l}0,779 \\
0,647 \\
0,775 \\
0,788 \\
0,688\end{array}$ & 0,786 & $\begin{array}{l}\text { Valid dan } \\
\text { Reliable }\end{array}$ \\
\hline 2 & Citra Merek & $\begin{array}{l}\text { CM } 1 \\
\text { CM } 2 \\
\text { CM } 3 \\
\text { CM } 4 \\
\text { CM } 5 \\
\text { CM } 6\end{array}$ & $\begin{array}{l}0,658 \\
0,704 \\
0,796 \\
0,669 \\
0,757 \\
0,725\end{array}$ & 0,810 & $\begin{array}{l}\text { Valid dan } \\
\text { Reliable }\end{array}$ \\
\hline 3 & Keputusan Pembelian & $\begin{array}{l}\text { KP 1 } \\
\text { KP } 2 \\
\text { KP } 3 \\
\text { KP } 4 \\
\text { KP } 5 \\
\text { KP } 6 \\
\text { KP } 7\end{array}$ & $\begin{array}{l}0,785 \\
0,546 \\
0,644 \\
0,775 \\
0,772 \\
0,757 \\
0,803\end{array}$ & 0,847 & $\begin{array}{l}\text { Valid dan } \\
\text { Reliable }\end{array}$ \\
\hline
\end{tabular}

Sumber : Data Diolah (2020)

Lampiran 2. Hasil Uji Normalitas 200 Responden Sebelum Pengurangan Outliers

\begin{tabular}{|l|r|r|r|r|r|r|}
\hline \multicolumn{1}{|c|}{ Variable } & \multicolumn{1}{c|}{ Min } & \multicolumn{1}{c|}{ Max } & \multicolumn{1}{c|}{ skew } & \multicolumn{1}{c|}{ c.r. } & \multicolumn{1}{c|}{ kurtosis } & \multicolumn{1}{c|}{ c.r. } \\
\hline PD7 & 1,000 & 5,000 &,- 545 & $-3,148$ &,- 479 & $-1,382$ \\
PD6 & 1,000 & 5,000 &,- 400 & $-2,310$ &,- 568 & $-1,638$ \\
PD5 & 1,000 & 5,000 &,- 272 & $-1,569$ &,- 271 &,- 782 \\
PD4 & 1,000 & 5,000 &, 028 &, 162 &,- 309 &,- 893 \\
PD3 & 1,000 & 5,000 &,- 403 & $-2,327$ &,- 622 & $-1,795$ \\
PD2 & 1,000 & 5,000 &,- 370 & $-2,134$ &,- 540 & $-1,558$ \\
PD1 & 1,000 & 5,000 &,- 513 & $-2,964$ &, 034 &, 098 \\
BI6 & 1,000 & 5,000 &,- 414 & $-2,393$ &, 148 & -426 \\
B15 & 1,000 & 5,000 &,- 153 &,- 884 &,- 089 &,- 257 \\
BI4 & 1,000 & 5,000 &, 079 &, 454 &,- 084 &,- 243 \\
BI3 & 1,000 & 5,000 &,- 690 & $-3,983$ &, 603 & 1,742 \\
BI2 & 1,000 & 5,000 &,- 645 & $-3,722$ &, 126 &, 364 \\
BI1 & 1,000 & 5,000 &,- 974 & $-5,621$ & 1,862 & 5,374 \\
CE5 & 2,000 & 5,000 &,- 474 & $-2,739$ &,- 453 & $-1,308$ \\
CE4 & 2,000 & 5,000 &,- 747 & $-4,312$ &, 501 & 1,445 \\
CE3 & 2,000 & 5,000 &,- 438 & $-2,528$ &,- 184 &,- 530 \\
CE2 & 2,000 & 5,000 &, 097 & -559 &,- 396 & $-1,143$ \\
CE1 & 1,000 & 5,000 & $-1,290$ & $-7,451$ & 2,915 & 8,414 \\
Multivariate & & & & & 55,868 & 14,722 \\
\hline
\end{tabular}

Sumber : Data Diolah (2020) 
Lampiran 3. Hasil Uji Normalitas 141 Responden Setelah Pengurangan Outliers

\begin{tabular}{|l|r|r|r|r|r|r|}
\hline \multicolumn{1}{|c|}{ Variable } & Min & Max & \multicolumn{1}{c|}{ Skew } & \multicolumn{1}{c|}{ c.r. } & kurtosis & \multicolumn{1}{c|}{ c.r. } \\
\hline PD7 & 2,000 & 5,000 &,- 426 & $-2,065$ &,- 512 & $-1,241$ \\
PD6 & 2,000 & 5,000 &,- 410 & $-1,989$ &,- 408 &,- 990 \\
PD5 & 2,000 & 5,000 &,- 160 &,- 776 &,- 235 &,- 571 \\
PD4 & 2,000 & 5,000 &, 141 &,- 682 &,- 519 & $-1,257$ \\
PD3 & 2,000 & 5,000 &,- 421 & $-2,039$ &,- 348 &,- 844 \\
PD2 & 2,000 & 5,000 &,- 397 & $-1,924$ &,- 516 & $-1,251$ \\
PD1 & 2,000 & 5,000 &,- 285 & $-1,381$ &,- 257 &,- 623 \\
BI6 & 2,000 & 5,000 &,- 014 &,- 066 &,- 892 & $-2,161$ \\
BI5 & 2,000 & 5,000 &, 172 &,- 835 &,- 543 & $-1,315$ \\
BI4 & 2,000 & 5,000 &, 515 & 2,498 &,- 364 &,,- 883 \\
BI3 & 3,000 & 5,000 &,- 187 &,- 905 &,- 705 & $-1,709$ \\
BI2 & 3,000 & 5,000 &,- 164 &,- 793 &,- 990 & $-2,399$ \\
BI1 & 3,000 & 5,000 &,- 203 &,- 983 &,- 601 & $-1,456$ \\
CE5 & 3,000 & 5,000 &,- 232 & $-1,124$ &,- 840 & $-2,036$ \\
CE4 & 3,000 & 5,000 &,- 370 & $-1,795$ &,- 674 & $-1,634$ \\
CE3 & 3,000 & 5,000 &,- 084 &,- 406 &,- 587 & $-1,422$ \\
CE2 & 2,000 & 5,000 &, 254 & 1,231 &,- 347 &,- 841 \\
CE1 & 3,000 & 5,000 &,- 249 & $-1,206$ &,- 623 & $-1,509$ \\
Multivariate & & & & & 9,657 & 2,137 \\
\hline
\end{tabular}

Sumber : Data Diolah (2020) 